\title{
ENSINAR É CRIAR POSSIBILIDADES PARA A TRANSFORMAÇÃO: REFLEXÕES EM TORNO DO ENSINO DA EDUCAÇÃO FÍSICA ESCOLAR
}

\author{
THAMIRIS IZIDORO DA SILVA \\ VIVIANE DE BONA \\ Universidade Federal de Pernambuco (UFPE), Recife, Pernambuco, Brasil
}

\begin{abstract}
Resumo: O presente artigo intenta abordar a prática da Educação Física escolar na perspectiva da Educação Libertadora. Tratando-se de uma reflexãoproblematização, tem o objetivo de analisar duas experiências vivenciadas no contexto da prática da Educação Física a fim de explicar as aproximações e distanciamentos da primeira com a segunda. As experiências relatadas trazem de maneira expressiva que ensinar exige competências que ultrapassam a dimensão do puro fazer. Ressalta-se por meio das intervenções que a prática educativa em Educação Física pode pensar-fazer o ensino para além do transferir conhecimento. Para isto, compreendeu-se a importância da relação educador-educando no processo educativo e o sentido da aprendizagem voltada não só a uma formação intelectual e física, mas a uma formação cidadã dos sujeitos, na direção de sua libertação.

Palavras-chave: Educação Física. Educação Libertadora. Prática Educativa. Transformação.
\end{abstract}

INICIANDO A CONVERSA

"ensinar não é transferir conhecimento, mas criar as possibilidades para a sua própria produção ou a sua construção". (FREIRE, 2005, p. 47)

A epígrafe acima foi escrita por um educador nordestino para o mundo. Tal pensamento desperta inquietações profundas, daquelas que há anos nos acompanham, embasando ações, provocando reflexões e alimentando a prática educativa.

Abordando, em especial, o contexto da Educação Física escolar, e sendo a primeira autora deste texto sujeita da prática docente dessa linguagem, pensamos ser pertinente refletir sobre a relação ensinar-aprender no contexto da prática pedagógica da Educação Física, perpassando por indagações que nos levam, também, a questionarmos a prática educativa das diferentes linguagens em espaços escolares, na essência de seu constante movimento de criação-recriação-transformação.

Assentado nesse propósito, o presente escrito ganha vida para problematizar a prática da Educação Física na perspectiva da Educação Libertadora, sendo esta uma educação que aproxima os sujeitos do ensino e da aprendizagem para a construção de saberes que levam à formação cidadã e à libertação das pessoas. É por isso que o 
diálogo entre a Educação Física e a Educação Libertadora torna-se uma oportunidade de exercitar essa formação cidadã individual, que se constrói no coletivo através das relações e das experiências compartilhadas.

Sendo assim, trazemos duas experiências vivenciadas por uma das autoras deste texto: a primeira ocorrida em 2017, no exercício da prática docente do estágio supervisionado, quando se cumpriu o movimento de ensinar e aprender nas aulas de Educação Física com as turmas do Ensino Médio, em uma escola do Recife; e a outra, uma experiência atual, agora não mais enquanto estudante do curso de Licenciatura em Educação Física, mas como professora de Educação Física, na continuidade da formação e do exercício profissional.

Para desenvolvermos a reflexão proposta, temos como objetivo analisar essas experiências sob a perspectiva da Educação Libertadora, como também explicar as aproximações e distanciamentos da primeira com a segunda experiência. Escolhemos dialogar com o pensamento de Paulo Freire presente nas seguintes obras: Pedagogia da Autonomia: saberes necessários a prática educativa (2005), Pedagogia do Oprimido (1987) e Educação como Prática da Liberdade (1967). As ideias de Freire fazem parte desta proposição por entendermos que nelas podemos encontrar elementos de melhor compressão quando transitamos entre as dimensões da prática educativa do ensino da Educação Física escolar, acreditando em um contexto de educação que faz questão de estimular o pensar autêntico de ambos os sujeitos da aprendizagem.

Tratando-se de uma reflexão-problematização, utilizamos como ponto de partida um relato de experiência produzido há três anos como material para ser analisado e revisitado, ${ }^{1}$ nesse compartilhar de experiências que permitiu a problematização, análise e explicação de práticas vivenciadas em contextos diferentes. Tal recorrência a relatos de experiência ocorre por acreditarmos que contribuíram e contribuem para a formação humana de uma professora de Educação Física que se fia na linguagem corporal como uma maneira de comunicação livre e autêntica, que corrobora para a construção de sujeitos mais humanos.

Portanto, convidamos a todas e todos a conhecerem um pouco mais do feito, das reflexões e do inacabado processo de construção cidadã e profissional.

\section{ENSINAR É CRIAR POSSIBILIDADES}

$\mathrm{O}$ ato de ensinar nos permite olhar sob uma diversidade de lentes, colocandonos diante de possibilidades que refletem na nossa formação, seja enquanto professora ou estudante. Nesse sentido, Paulo Freire (2005) nos estimula a olhar o ato de ensinar de maneira a compreender os sujeitos nas suas mais profundas razões de ser, ontológica, política, ética, epistemológica, pedagógica.

Levando em consideração esse olhar de Freire (2005), podemos afirmar que as experiências a serem compartilhadas não só permitiram conhecer melhor os sujeitos como também nos levaram a olhar para a prática educativa buscando mudança, problematização e construção de uma aprendizagem diferente.

Para tanto, faz-se importante compreender que essa busca esteve presente desde a primeira conversa em sala de aula com os estagiários do curso de Licenciatura 
em Educação Física sobre a intervenção até o seu último dia de prática, num exercício de conscientização do inacabado, o qual, ainda segundo o autor, é algo próprio do ser humano e que permite o reconhecimento do ser condicionado.

Sobre isso, Freire (2005, p. 54) afirma que existe "diferença entre o inacabado que não se sabe como tal e o inacabado que histórica e socialmente alcançou a possibilidade de saber-se inacabado". A observação de Freire (2005) nos provoca a pensar que toda prática educativa que vise criar possibilidades para a sua própria produção ou a sua construção pode ser um grande meio de conscientização desse ser inacabado que aprende com o mundo e com o outro, expressando essa aprendizagem através da leitura de mundo e da leitura da palavra - ou melhor dizendo, das palavras.

Essas palavras, segundo Paulo Freire (1987), devem ser autênticas, verdadeiras e humanas, possibilitando o que ele chama de "pronunciar o mundo", sob a compreensão de que "não é no silêncio que os homens se fazem, mas na palavra, no trabalho, na açãoreflexão" (FREIRE, 1987, p. 44). Assim, fica evidente que o autor não pensa a palavra como algo pronto, inacabado, mas como uma construção que nos leva a refletir sobre a prática educativa enquanto trabalho que permite ação-reflexão-nova ação.

No contexto educativo, esse movimento dialético de ação-reflexão-nova ação leva os sujeitos do ensino e aprendizagem ao diálogo que, se mediatizado pelo mundo, torna-se mais uma possibilidade criada através do ato de ensinar, pois, "se é dizendo a palavra com que, 'pronunciando' o mundo, os homens o transformam, o diálogo se impõe como caminho pelo qual os homens ganham significação enquanto homens" (FREIRE, 1987, p. 45). Nesta relação de interpretação do mundo com o mundo as práticas educativas tornaram-se dialógicas.

Contudo, ao perceber esses aspectos na prática educativa, torna-se indispensável o movimento de superação, "mesmo sabendo que as condições materiais, culturais, econômicas, sociais e políticas, culturais e ideológicas em que nos achamos geram quase sempre barreiras de difícil superação para o cumprimento de nossa tarefa histórica de mudar o mundo" (FREIRE, 2005, p. 54). Esse movimento de superação tornase uma construção diária e inacabada, que leva os sujeitos envolvidos a buscarem construir uma educação libertadora e que, por isso mesmo, enraíza-se "no amor, na humildade, na fé dos homens" (FREIRE, 1987, p. 46). Essa proposta de uma educação libertadora nos faz concordar ainda mais com Paulo Freire $(1967$, p. 35) quando diz que "não há educação fora das sociedades humanas e não há homem no vazio". Pois é, justamente, esse homem que, permitindo-se viver os processos educativos, sociais, culturais, dentre tantos outros, vai conseguir transformar o mundo.

Ainda sobre essas questões, chama muito a nossa atenção quando podemos refletir com Paulo Freire acerca do ser humano em suas relações e em sua diversidade, quando o autor afirma que essas relações guardam em si "[...] conotações de pluralidade, de transcendência, de criticidade, de consequência e de temporalidade" (FREIRE, 1967, p. 39), levando-nos a acreditar que é exatamente por isso que o ser humano tem essa capacidade de se reinventar e criar possibilidades para sua própria aprendizagem. Se adentrarmos mais ainda nos pensamentos de Freire (1967), veremos que o autor faz questão de falar dessa relação ser humano-mundo com a intenção de diferenciá-la apenas do puro contato que o humano estabelece no mundo e com o mundo. $O$ educador chama nossa atenção por explicitar essa relação, tratando de uma pluralidade singular, que pode ser visualizada: 
[...] nas relações do homem com o mundo, na medida em que responde à ampla variedade dos seus desafios. Em que não se esgota num tipo padronizado de resposta. A sua pluralidade não é só em face dos diferentes desafios que partem do seu contexto, mas em face de um mesmo desafio. No jogo constante de suas respostas, altera-se no próprio ato de responder. Organiza-se. Escolhe a melhor resposta. Testa-se. Age. Faz tudo isso com a certeza de quem usa uma ferramenta, com a consciência de quem está diante de algo que o desafia. Nas relações que o homem estabelece com o mundo há, por isso mesmo, uma pluralidade na própria singularidade (FREIRE, 1967, p. 39-40).

Sendo essa mesma relação que constitui uma pluralidade singular, podemos compreender que é nela que o ser humano se permite ensinar-aprender. Se pensarmos sobre isso, no sentido da prática educativa da Educação Física no ambiente escolar, podemos dizer que tal prática poderá proporcionar a construção de um conjunto de saberes que levem o ser humano a superar certos desafios na diversidade de espaços, culturas, implementos, sujeitos, movimentos. Tal consideração corrobora o pensamento de Freire $(2005$, p. 88) ao falar sobre a relação de ensino-curiosidade: "O exercício da curiosidade convoca a imaginação, a intuição, as emoções, a capacidade de conjecturar, de comparar, na busca da perfilização do objeto ou do achado de sua razão de ser." Desse modo, o desvendar de qualquer objeto caminha junto com a curiosidade que vamos trilhando sobre ele e as possibilidades de desafios que encontramos, buscando superá-los.

Neste relato, a Educação Física escolar nos permite pensar sobre uma prática inacabada, em constante construção e comprometimento com o outro e com o mundo. Um mundo que se nutre de mudanças que, por vezes, como lembra Paulo Freire (1967), apresenta-se numa marcha acelerada, fazendo a sociedade procurar sempre novas tarefas, temas, mudanças, sendo, por sua vez, processadas em tempos históricos diferentes, invariáveis, com passagens de uma época para outra, como vivemos desde as primeiras civilizações.

Nesse sentido, relacionar as experiências com a prática docente na escola, em contexto da Educação Física, não só consiste em compartilhar um feito e uma prática da atualidade, mas em situar que a prática educativa, por si só, não leva à transformação. Porém, o movimento de ação-reflexão-nova ação possibilita a reinvenção da prática que, não sendo conclusa, leva-nos a contribuir com o processo de humanização, sendo esta "[...] ameaçada constantemente pela opressão que o esmaga, quase sempre até sendo feita - e isso é o mais doloroso - em nome de sua própria libertação" (FREIRE, 1967, p. 42).

Por isso que falar de prática educativa, seja lá em qual contexto for, exige de nós a consciência de que não estamos certos de tudo que já foi elaborado, vivido. Precisamos revisitar o feito como uma possibilidade de aprender com ele, de problematizá-lo, de compará-lo, de olharmos para o contexto histórico da época. É uma oportunidade de olharmos para dentro de nossa pluralidade singular e assumirmos que dela podemos extrair duas coisas importantes: uma, trata-se daquilo que não foi possível 
analisar quando se estava vivendo, que é o passado; a outra se refere àquilo que, por vezes, Paulo Freire (1987) chama de 'situações limites e inéditos viáveis', que são as possibilidades de superação para um possível futuro.

É acreditando nisso que compartilhamos as memórias sobre uma experiência que, até hoje, provoca suspiros, inquietações, saudade. Essa experiência é revisitada porque sabemos que o contexto atual no qual nossa educação brasileira se encontra requer de nós, professores (as), um olhar crítico para os momentos em que vivemos a partir das relações com as realidades, em seu ato de criação, recriação e decisão, como um caminho de dinamizar o mundo. Ir aos poucos desativando o freio acionado sobre essa Educação Libertadora é necessário, como também é uma constante busca.

\section{DESENHANDO O MÉTODO}

Este texto, configurado enquanto um relato de experiência, refere-se a uma construção baseada em acontecimentos da vida real, embasados por aportes teóricos, expondo os problemas observados, os procedimentos, intervenções e técnicas utilizadas durante as experiências (GROLLMUS; TARRÉS, 2015).

Em sua elaboração, foi analisado o relato de experiência (primeira experiência) produzido e publicado em 2018 no Fórum de Estudos: leituras de Paulo Freire Legado e presença de Freire no Rio Grande do Sul, apresentado com o título Educação Física escolar: ensinar não é transferir conhecimento. Somado a esse relato, descrevemos a segunda experiência que, sendo mais atual, possibilitou o exercício da escrita e análise durante o pensar-fazer do presente texto.

Tais descrições foram realizadas e problematizadas a partir das ideias presentes nas obras de Paulo Freire $(1967 ; 1987 ; 2005)$, resgatando a importância do ato de ensinar Educação Física no exercício de uma Educação Libertadora. A análise dessas experiências buscou explicar as aproximações e distanciamentos da primeira com a segunda experiência vivida.

\section{REVISITANDO O FEITO: ENSINAR EXIGE CURIOSIDADE}

Movidas pela curiosidade epistemológica e existencial do ser, colocamo-nos à disposição para olhar o feito, não como quem olha um álbum de fotos e comenta sobre eles, mas como quem revisita a experiência vivida e busca problematizá-la teoricamente, destacando elementos que a tornara única.

Nesse sentido, referimo-nos à experiência compartilhada pela primeira autora com colegas de turma do curso de Licenciatura em Educação Física, quando, sob a condição da prática de estágio supervisionado, colocamo-nos à disposição do exercício da prática docente em turmas do Ensino Médio de uma escola pública de Recife. ${ }^{2}$

A Educação Física para essa fase escolar deve apresentar características próprias e inovadoras, que levem em consideração a fase cognitiva e afetivo-social que os adolescentes alcançaram (BETTI; ZULIANI, 2002). Além disso, a Educação Física deve ser enriquecida com conteúdos e vivências que produzam significados para os estudantes. Diante dessas observações, a experiência teve sua origem.

Visando alinhar as ideias de ensino dos estagiários ao plano de ensino do professor da escola, tivemos um primeiro contato para ouvir e direcionar nossa 
intervenção, acertando o compartilhamento de conhecimentos sobre os conteúdos de lutas e jogos. Tais conteúdos permitiram o trato com a contextualização histórica, com o contexto social dos estudantes, com a diversidade de culturas percebida nas diferentes formas de jogar e lutar.

Essa aproximação dos conteúdos ao contexto histórico e social dos estudantes nos leva a relacionar a diversidade de culturas percebida a partir dos conhecimentos com a importância do ato de estimular a pergunta, a reflexão crítica dessa pergunta, como também o que pretendemos com ela (FREIRE, 1967). A delimitação dos conteúdos, nesse sentido, não só nos direciona, mas nos faz enxergar diversas possibilidades de como abordá-los. Coloca-nos no lugar de sujeitos que, agora, devem pensar o ensino e seus impactos. E, nesse sentido, exercitar o ser professor que Paulo Freire (2005, p. 86) caracteriza como bom: "[...] o bom professor é aquele que consegue, enquanto fala, trazer o aluno até a intimidade do movimento de seu pensamento".

Considerar essa fala de Freire (2005) estimula o sujeito que assume a postura docente a organizar os conhecimentos de maneira a incentivar a implementação de temáticas sociais, históricas, construção de materiais, para estimular o trabalho coletivo, o compartilhar de ideias, as tomadas de decisões, o que permite, por sua vez, um movimento de transição, que segundo Freire (2005), faz com que o sujeito passe de uma curiosidade espontânea para a curiosidade epistemológica.

Esse fator permeou toda nossa experiência; as práticas tanto com o conteúdo jogos quanto com o conteúdo lutas trouxeram problematizações e relatos entre os estudantes que ultrapassaram a ideia de apenas descrever uma experiência, falando, assim, da vida, de história e de aprendizado. Essas problematizações permitiram o exercício da pergunta como uma maneira de estimular a pronúncia do mundo, ou seja, o encontro dos homens, o ato de criação (FREIRE, 1967).

Ao decorrer de cada prática, ficava mais evidente a importância daquela intervenção na vida de cada sujeito. As vivências apresentavam em sua ação possibilidades para continuarmos "[...] em processo de criação, que é a maneira humana de fazer cultura" (ROSAS, 2008 p. 31). Isso acontecia através da transformação das regras dos jogos, inicialmente propostos, nos quais os estudantes transformavam os jogos de salão em jogos populares, utilizando materiais de fácil acesso para a construção dos implementos necessários para o jogo.

Tal fato permitiu que os estudantes se expressassem através das ações e decisões durante esse momento de criação, estabelecendo relações com os conteúdos vistos, como também com os próprios colegas de turmas e estagiários. Acreditamos que esse estímulo a tomadas de decisões e à criação tornou-se um momento de buscar o que inaugura o diálogo da Educação Física atrelada a uma educação como prática da liberdade, pois foi um momento em que incentivamos a investigação do universo temático daqueles estudantes, assim como os "temas geradores" ${ }^{3}$ que embasaram nossas intervenções.

As últimas práticas educativas, vivenciadas em outubro de 2017, foram acompanhadas pela sensação de dever cumprido e de saudade daquilo que não iria mais se repetir. Encerramos esse dia ouvindo os estudantes, buscando uma avaliação sobre os que assumiram a postura docente neste período de prática. As falas, aos 
SILVA, T. I. da; BONA, V. de.

poucos, vieram. Os estudantes agradeceram nossa contribuição e elogiaram a maneira como estávamos mediando as práticas.

As falas apresentaram em sua essência elementos que nos levaram a refletir sobre a relação educador-educando construída durante toda a experiência; uma relação mediada pelo conhecimento de mundo, de sujeito e de vida. Relação que deve ser constituída com respeito, repleta de tudo aquilo que permite ao professor ou à professora, como diz Freire (2005), não se assustar com a afetividade, mas expressá-la. Significa, também, "[...] esta abertura ao querer bem a maneira que tenho de autenticamente selar o meu compromisso com os educandos, numa prática específica do ser humano" (FREIRE, 2005, p. 141).

É nesse sentido que problematizar essa primeira experiência na condição de estudante do curso de licenciatura, na atualidade, enquanto professora de Educação Física, é uma forma de reinventá-la, de atribuir outros sentidos e significados a uma prática que enfrentou os desafios de ter como campo uma escola pública brasileira, marcada por uma educação conservadora, e ter como sujeitos que assumiram a postura docente, estudantes que buscaram, por meio de suas práticas e da relação educadoreducando, avançar no caminho de superação dessa educação conservadora.

Diante disso, em harmonia com as ideias de Paulo Freire, caminhamos para problematizarmos a outra experiência, que, não mais importante que a primeira, apresenta a atualidade e a continuidade do ser docente, através da práxis. Hoje, existe a clareza de como foi e está sendo importante caminhar com essa busca constante por uma Educação Física que, unida a uma educação libertadora, é uma Educação Física que compreende e não julga; uma Educação Física que respeita as diferenças e não seleciona os melhores; uma Educação Física que é representada socialmente com respeito aos seus profissionais e não com discriminação e desigualdade; uma Educação Física que contribui de maneira ativa e constante com a saúde dos seus praticantes; uma Educação Física que busca ser a linguagem corporal que visa possibilitar de maneira livre e criativa a comunicação entre os povos.

\section{ENSINAR EXIGE A CONSCIÊNCIA DO INACABAMENTO: O 'ESTAR SENDO' EM EDUCAÇÃO FÍSICA ESCOLAR}

Conscientes de que estamos em constante processo de aprendizagem, o olhar agora se volta para o ser docente que, dentre tantas outras questões que surgem no decorrer do fazer docente, questiona-se: Que tipo de prática estou realizando? Qual a importância dela para a sociedade? Estou sendo útil no exercício da profissão? O que posso fazer para melhorar minha prática docente? Contudo, anterior aos questionamentos, existe um elemento que nos impulsiona a pensar sobre a nossa existência enquanto sujeitos inacabados e que, por isso, não realiza e nem responde de maneira isolada a nenhuma dessas perguntas.

Talvez nessas indagações encontremos a razão maior de concordar com Paulo Freire, porque ele faz com que possamos refletir e entender que, antes de tudo, somos humanos, criando possibilidades para um processo de conscientização, significando "[...] uma abertura à compreensão das estruturas sociais [...]" (FREIRE, 1967, p. 15). Esse processo pode ser uma resposta às problemáticas que emergem do campo educacional. Se pensarmos essa conscientização em contexto da Educação Física escolar, talvez possa 
ser um meio autêntico de mobilizar professores e estudantes e fazer com que, juntos, esclareçam reflexões que levam, muitas vezes, os sujeitos a desacreditarem em sua aprendizagem, sua competência profissional, sua representação, sua valorização.

É nesse sentido que trazer as problematizações de uma nova experiência que, diferentemente da primeira, é reencontrada cada dia com a sala de aula e com a prática educativa, irá permitir enxergar, cada vez mais, que ensinar exige - de fato e sem dúvidas - a consciência do inacabamento (FREIRE, 2005).

Antes mesmo de iniciar a problematização teórica sobre a temática, abrimos um parêntese para situar os (as) leitores (as) sobre o contexto em que nos encontramos ao escrever este texto. Enfrentando um período reconhecido socialmente como pandemia em função da Covid-19, possuímos a esperança de reencontrar o "chão da escola". Estamos presenciando uma escola que, hoje, está sendo uma plataforma digital e todos os ambientes acessíveis de nossas casas; estudantes que foram transformados em perfis e comentários em plataformas. Em especial, nas aulas de Educação Física, a quadra de esportes foi transformada em slides com fotos para nos aproximarmos de uma escola da qual há sete meses fomos afastados.

Esclarecidos (as) disso, relatamos a segunda experiência, também vivida apenas por uma das autoras deste texto, que antecede esse período pandêmico. Referimo-nos às vivências enquanto professora de Educação Física de turmas do Ensino Médio e Anos Finais do Ensino Fundamental ( $0^{\circ}$ e $9^{\circ}$ anos), no âmbito de uma escola particular em Recife; ministrando aulas com tais turmas, o que está sendo um desafio. Primeiro, porque a Educação Física nesses segmentos de escolarização incorpora objetivos que adentram no campo do aprofundamento do conhecimento. Segundo, porque com o Ensino Médio há uma cobrança gigantesca sobre o que diz respeito aos resultados nos exames e provas de vestibulares, o que acaba jogando a Educação Física para escanteio, para dar mais ênfase a outras disciplinas. Terceiro, porque trata-se de uma disciplina que trabalha diretamente com as questões corporais e os estudantes que compõem essas turmas estão passando por mudanças hormonais, corporais, comportamentais, que se refletem nas aulas e na aprendizagem em Educação Física.

Nesse contexto, compartilhamos a prática docente com mais cinco colegas de profissão que atuam nas turmas e planejam os conteúdos a serem aprendidos. Esse compartilhar de turma nos permite conviver com a pluralidade das relações humanas, a qual, segundo Freire (1987, p. 40), "não é só em face dos diferentes desafios que partem do seu contexto, mas em face de um mesmo desafio". Esses desafios, dentro dessa realidade, são voltados ao confronto de ideias, ao diálogo consciente sobre os conteúdos, aos planejamentos elaborados e outras questões, que colocam a equipe de Educação Física a aprender a aprender e conviver com as diferenças de pensamento e práticas.

Sob a consciência das diferenças entre um sujeito e outro, analisamos não mais o pessoal, o eu, mas os impactos das tomadas de decisões de diferentes professores diante de uma mesma prática educativa em Educação Física no contexto escolar. Falamos de profissionais que foram traçando sua formação continuada de diferentes maneiras. Uns optaram por fazer parte do time daqueles que carregam consigo os conhecimentos iniciais da formação acadêmica em Educação Física e os preservam. 
SILVA, T. I. da; BONA, V. de.

Outros buscam por dar continuidade a sua formação, cursando especializações e estudos mais detalhados sobre os objetos do conhecimento em Educação Física.

Tais diferenciações de interesses levam a equipe a olhar para a Educação Física salientando dois aspectos distintos: a manutenção de uma única Educação Física e a criação de novas possibilidades de Educação Física no ambiente escolar. Tais aspectos nos levam a refletir, de imediato, que as diferentes visões dentro de um coletivo, se não são tratadas como um diálogo, podem levar a prática educativa ao mero comodismo. Nesse sentido, faz-se necessária a busca constante pela aproximação e entendimento dessa prática educativa, sob a clareza de que quanto mais se reconhece a responsabilidade que essa prática exige dos sujeitos, mais fica evidente que ela está atrelada à "[...] capacidade de fazer justiça, de não falhar à verdade" (FREIRE, 2005, p. 98), exercendo a ética de testemunhar aquilo que é realizado na prática educativa.

Trazer para essa prática educativa da Educação Física o exercício da conscientização pela compreensão de um mundo que "[...] não se estruturam sincronicamente numa estática consciência do mundo: visão e espetáculo" (FREIRE, 1987, p. 8) é de extrema importância e deve estar presente desde o momento do planejamento até as reflexões após a prática. O exercício de conscientização é um fator que não é vivenciado quando os sujeitos que assumem a postura docente deixam de lado o objetivo da aprendizagem e começam a olhar para o seu próprio conforto, no sentido do trabalho e, quando isso ocorre, o contexto também se transforma em um fator a ser problematizado.

Inserida em uma realidade que podemos considerar privilegiada - se pontuarmos o cenário de educação brasileira e, de maneira mais específica, as condições disponibilizadas para as aulas de Educação Física -, nos referimos ao que consiste em ser uma realidade que proporciona os melhores materiais para a prática, como também ambientes confortáveis, recursos tecnológicos e outros aspectos que dizem muito mais da relação sujeito-objeto - que é importantíssima - contudo, não é a relação que sustenta uma prática educativa de qualidade em Educação Física.

Ao longo dessa experiência, dia após dia, reafirmamos que as relações que devem estar mais sólidas dentro de uma prática educativa são as relações entre os sujeitos. São elas que irão permitir o desenvolver de um bom planejamento, que estabeleça objetivos possíveis para a realidade; são elas que irão permitir o reconhecimento da importância de um determinado conteúdo a ser estudado; são elas que irão permitir a construção de possibilidades criativas para a utilização dessa riqueza de materiais e, principalmente, são elas que irão permitir o reconhecimento da Educação Física enquanto parte de uma construção coletiva e que, para além da construção, tornase uma intervenção no mundo e com o mundo. Principalmente, quando compreendemos "[...] que a educação é afirmação da liberdade e toma as palavras a sério - isto é, quando as toma por sua significação real - se obriga, neste mesmo momento, a reconhecer o fato da opressão, do mesmo modo que a luta pela libertação" (FREIRE, 1967, p. 6).

Por vezes, diante de todos esses aspectos, comparamos as realidades em que aconteceram/acontecem as experiências. Refletimos sobre: como os fatores sociais influenciam nas práticas educativas; como os educandos e seus comportamentos diante de uma disciplina contribuem ou não com o êxito da aprendizagem; como é possível, depois de anos de uma primeira experiência, continuar se deparando com 
enfrentamentos iguais a um outro período. Todas essas reflexões nos levam a acreditar que estamos no caminho certo - e pretendemos não desistir.

Queremos olhar cada vez mais a fundo para dentro de nossa própria caminhada porque, assim como Paulo Freire (2005, p. 94), "[...] me movo como educador porque, primeiro, me movo como gente". Acreditamos que é nesse movimento de revisitar, reinventar, recriar que podemos superar certas desigualdades e discriminações que venham a aparecer em nossas práticas. Acreditamos, também, que o que trazemos no contexto da Educação Física tem as suas particularidades, mas compreende elementos que andam de mãos dadas a pessoas, disciplinas e educações que acreditam na superação e na humanização dos povos.

Compreende-se, hoje, que a Educação Física pode ser considerada um dos meios de intervenção no mundo, por estar sendo um conhecimento em construção, contendo conteúdos que "[...] bem ou mal ensinados e/ou aprendidos, implica tanto o esforço de reprodução da ideologia dominante quanto o seu desmascaramento" (FREIRE, 2005, p. 98, grifo do autor). Isso implica dizer que a Educação Física se torna a prática observada, comparada, avaliada, escolhendo, decidindo, intervindo, rompendo, optando, construindo uma relação ética que permite ampliar as possibilidades no sentido da transformação humana.

Por isso que, caminhando para as considerações finais, compartilhamos com vocês uma 'derradeira' problematização - como diz um mestre de capoeira amigo ao se referir a algo que está chegando ao seu fim, mas que não se esgota ali - a respeito das aproximações e distanciamento entre as duas experiências apresentadas neste texto. Dessa feita, questionamos: qual experiência se colocou mais próxima diante daquilo que se acredita ser uma educação libertadora?

\section{ENSINAR EXIGE ALEGRIA E ESPERANÇA: UM OLHAR SOBRE AS EXPERIÊNCIAS AQUI RELATADAS}

Acreditamos que dizer das relações humanas é tratar da realidade considerando as contradições, as possibilidades de transformação e, também, o que se nega do sujeito enquanto ser de autonomia. Não sendo diferente na prática educativa em Educação Física no contexto escolar, pensamos que será no envolvimento de uma prática crítica, moral e gnosiológica que os sujeitos irão se aproximar da educação como prática da liberdade, de uma educação que reconhece os fatores das mais variadas formas de opressão e busca superá-las.

Nesse sentido, diante das duas experiências problematizadas anteriormente, podemos afirmar que ambas se aproximaram dessa educação adjetivada de libertadora. Pode parecer contraditório se, ao lerem essa afirmação, pensarem apenas em um possível resultado fabuloso da prática. Mas, se olharem para essa afirmação como algo dito e direcionado ao processo e às variabilidades da realidade, logo irão concordar com a assertiva a partir de Paulo Freire (1987), quando esclarece que essa educação que liberta só será alcançada num exercício constante de respeitar a participação livre e autêntica do ser humano. E foi isso que se buscou exercitar em cada prática, mesmo tratando-se de realidades e tempos diferentes.

Essa constante busca fez perceber que as aproximações e distanciamentos de uma prática com a outra não estão apenas em elementos concretos e de fácil 
SILVA, T. I. da; BONA, V. de.

objetivação; estão, também, em sensações alimentadas dentro de quem viveu, durante cada prática vivida. Dizemos da alegria e da esperança que o ato de ensinar exige. $\mathrm{Na}$ primeira experiência, essas sensações foram acompanhadas de um olhar ingênuo para a realidade e para as práticas pedagógicas. Imaginava-se uma intervenção sem problemas, em que se iria conseguir colocar em prática tudo aquilo que era lido nos livros sobre metodologia da Educação Física escolar; o que, de fato, não aconteceu hoje se compreende, mas na época foi algo crucial. Perceber que nem tudo sairia como os livros apresentavam foi frustrante por um momento, até se perceber que a prática não é a reprodução da teoria, mas é uma ação que caminha com a mediação dela.

Na segunda experiência essa percepção fica mais evidente. Perceber enquanto professora que não somos detentoras de todo conhecimento foi libertador. Aprender que a esperança junto à do educando pode nos levar a aprender mais, a ensinar, a inquietar-nos, a "produzir e juntos igualmente resistir aos obstáculos a nossa alegria" (FREIRE, 2005, p. 72), foi essencial para o que hoje reconhecemos como formação humana.

Além disso, as experiências permitiram pensar na superação de contradições epistemológicas e sociais que não se iniciam apenas no momento da prática, mas que integram todo o processo do despertar da consciência crítica.

Nesse sentido, o pensar-fazer em Educação Física buscando desativar o freio da educação libertadora tornou-se o grande desafio do ensino e do ato de ensinar nas duas experiências. Mesmo estando incluídos no cenário de uma educação bancária, compreendemos, assim como Freire (2005, p. 47), que "[...] ensinar não é transferir conhecimento, mas criar as possibilidades para a sua própria produção ou a sua construção".

Na Educação Física escolar essas possibilidades recaem sobre o incentivo ao ensino problematizador, de um ensino crítico que pode ser entendido como "[...] a apropriação ativa e consciente do conhecimento" (COLETIVO DE AUTORES, 1992, p. 17). Como também recaem sobre o exercício de uma Educação Física que incorpora a construção dos seus próprios materiais, enquanto "[...] uma estratégia educacional para lidar com a dependência que alguns professores têm em relação aos materiais 'oficiais' (tais como bolas, redes e outros acessórios que já vêm prontos) e para trabalhar temas transversais como o meio ambiente e o consumo" (PEIXOTO; AZEVEDO, 2017, p. 17).

Assim, deve-se levar a compreensão de que a Educação Física não se limita aos "inéditos viáveis" causados pelos objetos, mas deve buscar a superação com estratégias e metodologias que enxerguem a beleza da corporalidade humana diante de suas possibilidades de recriação. Essa mesma corporalidade permite o fazer criativo, a comunicação e interação dos homens, no sentido de sua busca pela humanização das relações entre si e com a natureza (OLIVEIRA, 1998). A corporalidade traz para a prática educativa em Educação Física escolar o constante exercício da linguagem, poder e trabalho, estruturantes de uma sociedade.

Por causa de tal compreensão que as práticas educativas compartilhadas buscaram, dentro de seus limites e possibilidades, superar a ideia de que na relação educador-educando "[...] o educador é o que educa; os educandos são os educados" (FREIRE, 1987, p. 67). Essa ideia é característica de uma educação conservadora, em que compete a ela o ato de depositar, de transferir conhecimento, transformando o educando no seu depósito. 
Diante disso, podemos considerar que é de extrema importância nós, professores-estudantes, não deixarmos a alegria e a esperança morrerem em nossas práticas educativas, sejam elas em qual contexto for. Seguiremos acreditando que é na relação educador-educando, em contexto de uma educação que pensa o ato de ensinar para além do transferir conhecimento, que se legitima a construção de saberes necessários à prática educativa, esses que, bem retratados por Paulo Freire (2005), convidam-nos a acreditar que: ensinar exige a consciência do inacabado; ensinar exige respeito à autonomia do ser educando; ensinar exige bom-senso; ensinar exige humildade, tolerância e luta em defesa dos direitos dos educandos; ensinar exige apreensão da realidade; ensinar exige alegria e esperança; ensinar exige a convicção de que a mudança é possível; ensinar exige curiosidade.

Sendo assim, enxergar no ato de ensinar a possibilidade de ir além da transferência do conhecimento, do puro fazer por fazer, é, também, o que diferencia os educadores e educandos que lutam pela transformação social, dos educadores e educandos que se calam diante do já posto. Seguimos acreditando que é na relação ensinar-aprender que os homens ficam mais próximos e confiantes sobre a sua transformação e liberdade. Por fim, sugerimos que a realidade não seja olhada pensando que não há como mudar.

\section{TENTANDO CONCLUIR...}

Diante do exposto, constatamos que o ato de ensinar nos permite extrair das duas experiências elementos que nos ajudam a problematizar, analisar e compreender o feito, tanto sobre o que reflete na formação do professor quanto do estudante, ficando evidente que ensinar exige de nós competências que ultrapassam a dimensão do puro fazer.

As experiências aqui relatadas trouxeram isso de maneira expressiva, pois ressaltaram que a prática educativa em Educação Física no contexto da escola básica pode pensar-fazer o ensino para além do transferir conhecimento, e que, para isso, precisa compreender a importância da relação educador-educando no processo educativo, como também ter clareza sobre o sentido da aprendizagem que, nesse caso, trata-se da aprendizagem que possibilita a formação cidadã dos sujeitos, na direção de sua libertação.

Podemos destacar, também, a importância dos ambientes das experiências escolas de distintas realidades, mas que ambas trouxeram elementos para problematizarmos o ensino, assim como a própria organização dos conteúdos, as maneiras de aproximação entre os sujeitos da aprendizagem e a influência da formação profissional na prática educativa.

Ousando olhar essas relações como algo inacabado e inconcluso, acreditamos que alcançamos o objetivo de problematizar teoricamente as experiências de práticas educativas em contexto da Educação Física no ambiente escolar pela lente dos escritos de Paulo Freire. Consideramos que por meio desse esforço podemos estimular outros (as) professores (as) - e de modo especial, mas não exclusivo - os (as) professores (as) de Educação Física a se voltarem para as suas próprias práticas como algo que requer um 
SILVA, T. I. da; BONA, V. de.

olhar sensível, atento, gentil e curioso, por meio do qual os sujeitos da práxis possam ser interpretados enquanto sujeitos de cultura, de história e de conhecimento; sujeitos que podem aprender no coletivo que ensinar é, antes de tudo, uma maneira de intervenção no mundo, com o mundo e com o outro; que ensinar cria possibilidades para a transformação.

Artigo recebido em: 27/02/2021

Aprovado para publicação em: 29/06/2021

TEACHING IS CREATING POSSIBILITIES FOR THE TRANSFORMATION: REFLECTIONS ABOUT SCHOOL PHYSICAL EDUCATION TEACHING

ABSTRACT: This article intends to approach the practice of Physical Education at school from the perspective of Liberating Education. As a reflection-problematization, it aims to analyze two experiences lived in the context of the practice of Physical Education in order to explain the approximations and distances between the first and the second. The experiences reported expressively show that teaching requires skills that go beyond the dimension of pure action. It is highlighted through the interventions that the educational practice in Physical Education can to think-do teaching beyond the transfer of knowledge. For this, it was understood the importance of the teacher-student relationship in the educational process and the meaning of learning aimed not only at an intellectual and physical formation, but also a citizen formation of the subjects, towards their liberation.

KEYWORDS: Physical Education. Liberating Education. Educational Practice. Transformation.

\section{LA ENSEÑANZA GENERA POSIBILITAD PARA EL CAMBIO: REFLEXIONES CERCA DE LA ENSEÑANZA EN LAS CLASES DE EDUCACIÓN FÍSICA}

RESUMEN: Este artículo pretende acercar la práctica de la Educación Física en la escuela desde la perspectiva de la Educación Liberadora. Como reflexión-problematización, pretende analizar dos experiencias vividas en el contexto de la práctica de la Educación Física con el fin de explicar las aproximaciones y distancias entre ellos. Las experiencias lo dejan claro que la enseñanza requiere habilidades que van más allá de la dimensión del puro hacer. Se destaca a través de las intervenciones que la práctica educativa en Educación Física puede pensar-hacer enseñar más allá de la transferencia de conocimientos. Para ello, se entendió la importancia de la relación educador-alumno en el proceso educativo y el significado del aprendizaje dirigido no solo a una formación intelectual y física, sino también a una formación ciudadana de los sujetos, hacia su liberación.

PALABRAS CLAVE: Educación Física; Educación Liberadora; Práctica Educativa. Cambios. 


\section{NOTAS}

1 - O referido relato de experiência teve autoria de Thamiris Izidoro da Silva e foi publicado no ebook do XX Fórum de Estudos: leituras de Paulo Freire Legado e presença de Freire no Rio Grande do Sul, em 2018.

2 - Relembramos que essa vivência foi anteriormente publicada em forma de relato de experiência.

3 - "Ainda que essa postura - a de uma dúvida crítica - seja legítima, nos parece que a constatação do 'tema gerador', como uma concretização, é algo a que chegamos através, não só da própria experiência existencial, mas também de uma reflexão crítica sobre as relações homem-mundo e homens-homens, implícitas nas primeiras" (FREIRE, 1987, p. 50).

\section{REFERÊNCIAS}

BETTI, M.; ZULIANI, L. R. Educação física escolar: uma proposta de diretrizes pedagógicas. Revista Mackenzie de Educação Física e Esporte, Bauru-SP, ano 1, n. 1, p. 73-81, 2002.

COLETIVO DE AUTORES. Metodologia do Ensino da Educação Física. São Paulo: Cortez, 1992.

FREIRE, P. Pedagogia da autonomia: saberes necessários à prática educativa. 31. ed. São Paulo: Paz e Terra, 2005.

FREIRE, P. Pedagogia do Oprimido. 17. ed. Rio de Janeiro: Paz e Terra,1987.

FREIRE, P. Educação como Prática da Liberdade. Rio de Janeiro: Paz e Terra,1967.

GROLLMUS, N. S.; TARRÈS, J. P. Relatos metodológicos: difractando experiências narrativas de investigación. Fórum Qualitative Social Research, Berlim, v. 16, n. 2, p. 1-24, mayo 2015.

OLIVEIRA, M. A. T. Existe espaço para o ensino da Educação Física na escola básica? Pensar a prática, Goiânia, v. 2, n. 1, 1-23, jun./jul.,1998.

PEIXOTO, R. P.; AZEVEDO, I. O. S. Materiais alternativos nas aulas de educação física: possibilidades e desafios. Temas em educação física escolar, Rio de Janeiro, v. 2, n. 1, p. 15-29, jan./jun. 2017.

ROSAS, A. S. Criatividade em Educação Popular: um diálogo com Paulo Freire. 2008. 323 f. Tese (Doutorado em Educação) - Centro de Educação, Universidade Federal da Paraíba, João Pessoa, 2008. 
SILVA, T. I. da; BONA, V. de.

Thamiriz IzIDORO dA SILVA: Mestranda em Educação na Universidade Federal de Pernambuco (UFPE), na cidade de Recife.

Orcid: https://orcid.org/0000-0001-6427-5079

E-mail:vinharibas@hotmail.com

VIVIANe DE Bona: Professora do Programa de Pós-Graduação em Educação e do Mestrado Profissional em Educação Básica do Centro de Educação da UFPE, na cidade de Recife.

Orcid: https://orcid.org/0000-0003-2985-4133

E-mail: viviane.bona@ufpe.br

Este periódico utiliza a licença Creative Commons Attribution 3.0, para periódicos de acesso aberto (Open Archives Initiative - OAI). 